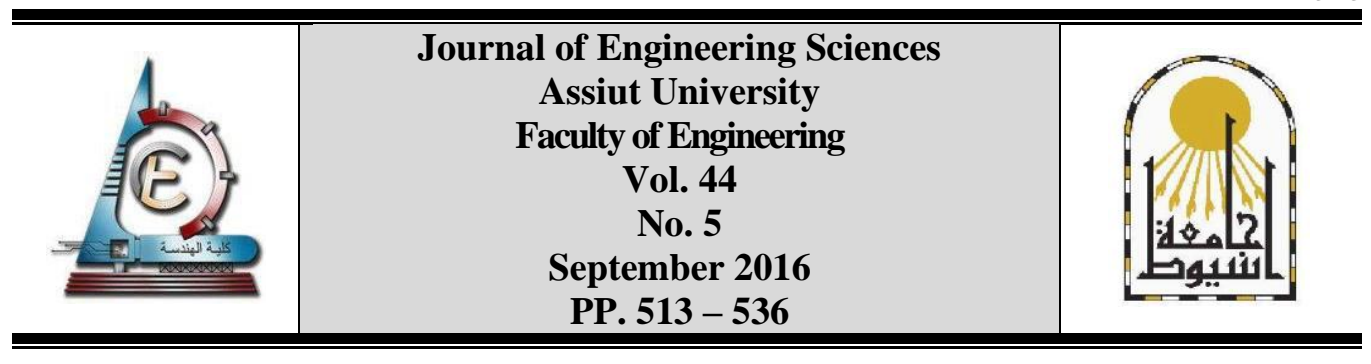

\title{
IRREGULARITY EFFECTS ON THE SEISMIC PERFORMANCE OF L-SHAPED MULTI-STORY BUILDINGS
}

\author{
Momen M. M. Ahmed ${ }^{1}$, Shehata E. Abdel Raheem ${ }^{2}$, \\ Mohamed M. Ahmed ${ }^{3}$ and Aly G. A. Abdel-Shafy *, 4 \\ ${ }^{1}$ M. Sc. Student, Civil Eng. Depart. Faculty of Engineering, Assiut University, Egypt \\ ${ }^{2,3,4}$ Civil Engineering Department, Faculty of Engineering, Assiut University, Egypt
}

Received 21 June 2016; Accepted 20 July 2016

\begin{abstract}
Past and recent earthquakes events demonstrate that buildings with configuration irregularity are more vulnerable to earthquake damages. So it's essential to investigate the seismic response of these structures in active seismic zones to reduce the potential seismic damages. The configuration irregularities introduce major challenges in the seismic design of building structures. One such form of irregularity is the presence of re-entrant corners that causes stress concentration due to sudden changes in stiffness and torsion amplification in the buildings; hence causes early collapse. This, the conventional design codes have not recommendations for proper evaluation of these buildings yet. Thus, a constructive research into re-entrant corner irregularity problems is essentially needed greater than ever. The objective of this study is to grasp the seismic behavior of the buildings with irregular plan of L-shape floor plan through the evaluation of the configuration irregularity of reentrant corners effects on measured seismic response demands. The measured responses include inter-story drift; story shear force; overturning moment; torsion moment at the base and along the building height; top floor displacement; and torsional Irregularity Ratio. Three dimensional finite element model of nine stories moment resisting frame buildings as reference model is developed; six L-shaped models are formulated with gradual reduction in the plan of the reference model. The models are analyzed with ETABS using Equivalent Static Load (ESL) and Response Spectrum (RS) Methods. The results prove that buildings with severe irregularity are more vulnerable than those with regular configuration resulting from torsion behavior, and the additional shear force produced in the perpendicular direction to the earthquake input. Also, in the codal empirical equation for the calculation of fundamental period of vibration could not grasp significant higher vibration modes such as torsional vibration of irregular buildings that could significantly affect seismic demands.
\end{abstract}

Keywords: Configuration Irregularity; L-shaped Buildings; Seismic demands; Torsional Irregularity Ratio.

\section{Introduction}

Earthquakes are one of the most unpredictable and devastating of natural disasters. Although, the occurrence of earthquakes cannot be predicted and prevented but the

* Corresponding author.

Email address: xmomen90@gmail.com 
structures should be designed to resist earthquake forces. The structure should possess main attributes to perform well in earthquake, such as simple and regular configuration, adequate lateral strength, stiffness and ductility [1]. So, selection of the structure's basic plan configuration plays a critical role in the structural design. The decision on the conceptual design will influence the ability of the structure to withstand earthquake ground shaking [2]. In addition, Modern construction demands the architect to plan irregular buildings in plan and elevation. The structural engineer on the other hand has a major responsibility to make the structure safe against all external forces; when such irregular buildings are constructed in a high seismic zone, the structural engineer's role becomes further challenging. So ideal and clear understanding of the behavior of irregular structures during earthquake is significant for structural engineers [3].

The behavior of a building during earthquakes depends critically on its overall shape, size and geometry, in addition to how the earthquake forces are shaking the ground. Hence, at the planning stage itself, architects and structural engineers must work together to ensure that the unfavorable features are avoided and a good building configuration is chosen [4]. In these modern days, most of the structures are involved with architectural importance and it is highly impossible to plan with regular shapes. These irregularities are responsible for the structural collapse of buildings under the action of dynamic loads. Hence, extensive research is required for achieving ultimate performance even with a poor configuration [5]. Therefore, this study aims to enhance the understanding and evaluation of seismic behavior for horizontal irregular buildings. The irregularities of the asymmetric distribution of mass, stiffness and strength are main source of severe damages due to excessive floor rotations and translations [6]. Moreover, torsional effects could significantly amplify the seismic response of buildings. So, the design of irregular buildings needs special care and enhancement of member sizes at regions of Irregularity. The plan configurations of structure have significant impact on the seismic response of structure in terms of displacement, story drift, and story shear demands [7]. Thus, decisions on building configuration at the planning stage are more important. For higher and unsymmetrical buildings, Response Spectrum Method should be used, while for the symmetric building; the lateral load equivalent method could be used [8, 9]. While, simple analysis methods are available for designing regular structures, however the use of simple methods is restricted by code regularity limits that lack proper analytical justification. Simple analysis methods such as (ESL) method could underestimate the actual demands and produce unsafe structures for irregular buildings [10].

This study objective is to grasp the seismic behavior for plan irregular building in a form of L-shaped buildings through the evaluation of the lateral forces, overturning moment, torsion action at base and each story level. Whereas the shear and overturning moment at the base are evaluated of special interest as the design values that specified in building Codes. A comparison study is introduced between the codal and analytical estimation of fundamental time period for regular and gradually irregular structures. Moreover, an accurate evaluation of the effects of irregularities in floor-plan configuration on the overall response of a building is introduced for the assessment of potential damage. So the seismic performance in terms of lateral story displacement, story drift ratio, center of mass displacement and torsional irregularity ratio for irregular L-shaped building models is investigated and compared to that of reference symmetric model. The outcomes results confirm the significant effects of the plan configuration irregularity on the seismic demands that necessitate a close collaboration between the architect and the engineer from the earliest planning stage of building to ensure a 
Momen M. M. Ahmed et al., Irregularity effects on the seismic performance of l-shaped ..........

good outcome, guarantee structural safety, reduce vulnerability, and limit costs. Since, a satisfactory seismic performance requires careful attention to analysis, design, and detailing and good construction practice $[11,12]$.

\section{Code provisions for torsional irregularity}

Configuration irregularity describes the layout of structure both in plan and elevation. The term encompasses a global 3D appreciation of how structure and building massing integrated to achieve seismic resistance [13]. In the present scenario, majority of the buildings have irregular configurations which can be either in plan or elevation or both [14]. While configuration alone is not likely to be the sole cause of building failure, it may be a major contributor. Historically, before the use of steel and reinforced concrete construction, good configuration was one of the major determinants of good seismic performance [15]. These irregularities are categorized as the following: First; the vertical irregularities that refer to sudden change of strength, stiffness, geometry and mass result in irregular distribution of forces or distribution over the height of the building. Second; the plan irregularities which refer to asymmetrical plan shapes or discontinuities in the horizontal resting elements (diaphragms) such as cut-outs, large openings, re-entrant corners and other abrupt changes resulting in torsion, diaphragm deformations and stress concentration [1]. The presence of irregularities is considered as a major deficiency in the seismic behavior of structures. One such form of irregularity is the presence of re-entrant corners which causes stress concentration due to sudden changes in stiffness and torsion in the buildings due to plan asymmetry [16].

Building Plans with re-entrant corner forms are a most useful set of building shapes for urban sites, particularly for residential apartments and hotels, which enable large plan areas to be accommodated in relatively compact form, yet still provide a high percentage of perimeter rooms with access to air and light. L-shaped and C-shaped buildings with reentrant corners are common for school buildings to accommodate spaces for playgrounds and assembly areas. But these configurations pose a great deficiency in the seismic behavior of the structure [17]. Most of the building codes recognize re-entrant corners as one of the serious irregularities in buildings but no vital recommendations for proper evaluation of these structures yet or incorporation way of retrofit strategies leads to accurate design methods. The evaluation of torsional provisions in buildings codes based on computed responses of elastic as well as inelastic, asymmetric-plan systems has been the subject of numerous studies in the past [18-21]. However, the constructive conclusions of these studies may not be generally applicable to code-designed buildings because the assumed plan-wise distribution of stiffness and strength is not representative of codedesigned buildings and the strength distribution can significantly influence the inelastic response [19]. If a design has a poor configuration to start with, all the design engineer can do is to provide a Band-Aid to improve a basically poor solution as best as it could be. Conversely, if a design starts-off with a good configuration and reasonable framing system, even a poor engineer can't harm its ultimate performance too much [22]. There are two problems created in L-shape buildings. The first is that they tend to produce differential motions between different wings of the building that, because of stiff elements that tend to be located in this region, result in local stress concentrations at the re-entrant corner, or notch as shown in Fig. 1 The second problem of this form is torsion, which is caused because the center of mass and the center of rigidity in this form cannot geometrically coincide for all possible earthquake directions. The result is a rotation. The 
resulting forces are very difficult to analyze and predict [23]. Therefore, Irregular structures need a more careful structural analysis to reach a suitable behavior during a devastating earthquake [24] as shown in Fig. 2. Continuity between structural components is vital for the safe transfer of the seismic forces to the ground. Failure of buildings during earthquakes is often due to the inability of their parts to work together in resisting lateral forces. Structural damage may occur at any point in the system if the lack of sufficient resistance exists at that location. Partial failure does not necessarily cause the collapse of a structure. The link between structural components and connections is more complex than the in-series system when it comes to structural damage, earthquakes are likely to find the weakest link in any complex system and cause damage to the most vulnerable element. Unexpected load paths and overstress of components can cause significant adverse effects. To prevent unfavorable failure modes, adequate conceptual design is required at an early stage. In addition, thorough assessment of the structural configuration is vital to achieve adequate seismic performance [25]. Further, Buildings with irregular shapes, particularly with re-entrant corners, exhibit special modes of oscillation, in addition to translational (pure/ diagonal) or torsional modes as shown in Fig. 3.

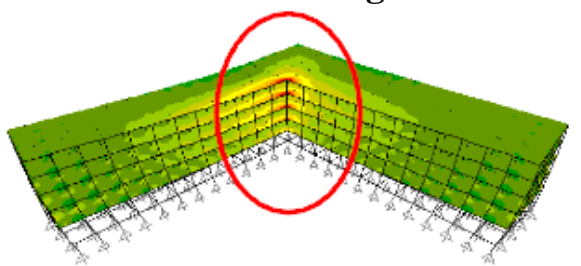

Fig. 1. Stress concentration at re-entrant corner in L-shaped buildings
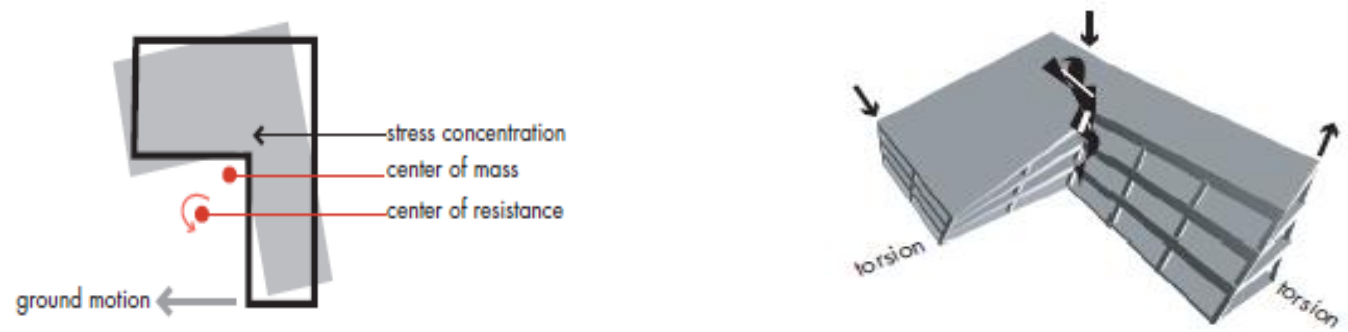

Fig. 2. Damage at re-entrant corner in L-shaped buildings
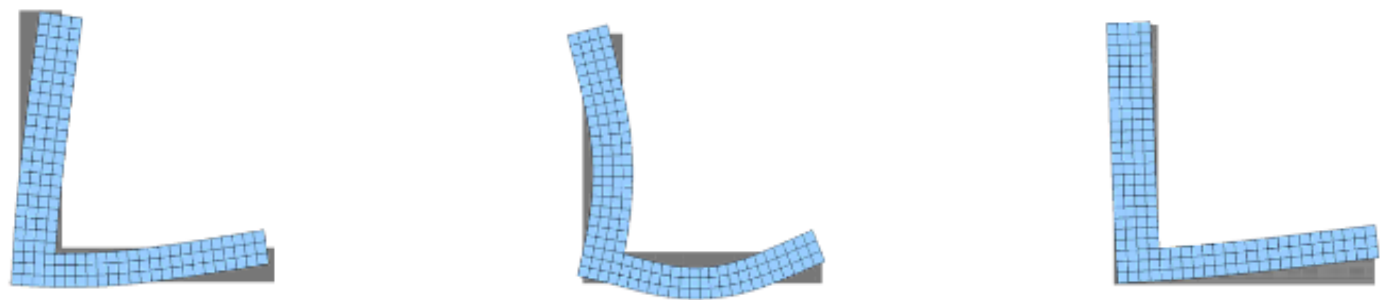

Fig. 3. Significant Modes of vibration for L-shaped building

\section{Analysis methodology}

Analysis methods are widely characterized as linear and nonlinear static and dynamic. The main difference between the equivalent static procedure and dynamic analysis procedure lies in the magnitude and distribution of lateral forces over the height of the buildings. In the dynamic analysis procedure, the lateral forces are based on properties of the natural vibration modes of the building, which are determined by the distribution of 
Momen M. M. Ahmed et al., Irregularity effects on the seismic performance of l-shaped ..........

mass and stiffness over height. In the equivalent lateral force procedure, the magnitude of forces is based on an estimation of the fundamental period and on the distribution of forces as given by a simple formula that is appropriate only for regular buildings [26]. In the preliminary design process, equivalent static seismic forces are used to determine the design internal forces of structural members using linear elastic analyzes of structure and, in turn, determine the design member strength demands. Such static seismic forces are simply determined corresponding to the elastic design acceleration spectrum divided by a structural strength reduction factor particularly called: the response modification factor $\mathrm{R}$ (UBC 1997, ECP-201 2012) [27-29]; the structural behavior factor, q (EC8 2004) [30]; or the structural factor, $D_{s}$ (AIJ 1999) [31]. Usually, the elastic design spectrum, which is often related to $5 \%$ or $10 \%$ Probability of Exceedance $(P O E)$ in 50 years, is defined smoothly as a reasonable representation of the seismic action demand on the structure at the site of interest. The adopted strength reduction factor is thus intended to represent an expected inelastic response demand or expected damage level demand, which may be induced during earthquake excitation [32].

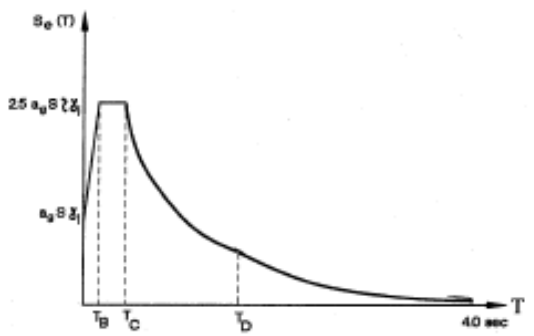

(a)Type 1

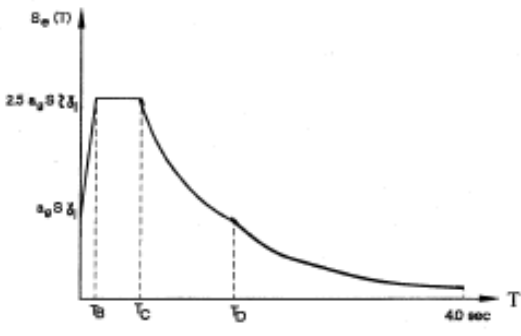

(b) Type 2

Fig. 4. ECP-201 Design Response Spectrum

\subsection{Equivalent static load (ESL) method}

Along the principal direction, the total design lateral force or design base shear is given in terms of design horizontal seismic coefficient and seismic weight of the structure. Design horizontal seismic coefficient depends on the zone factor of the site, importance of the structure, response reduction factor of the lateral load resisting elements and the fundamental period of the structure [33]. According to the ECP-201 (2012) [28], the seismic base shear force, $F_{b}$ for each horizontal direction in which the building is analyzed, shall be determined using the following expression:

$$
\mathrm{F}_{\mathrm{b}}=S_{d}\left(\mathrm{~T}_{1}\right) \times \lambda \times \mathrm{W} / \mathrm{g}
$$

Where: $S_{d}\left(T_{1}\right)$ is the ordinate of the design spectrum at period $T_{l} ; T_{1}$ is the fundamental period of vibration of the building for lateral motion in the direction considered; $W$ is the total weight of the building, above the foundation level; $g$ is the gravity acceleration; $\lambda$ is the effective modal mass correction factor, the value of which is equal to: $\lambda=0.85$ for $T_{1} \leq 2 T_{\mathrm{C}}$, and $n>2$ stories or $\lambda=1.00$ for $T_{1}>2 T_{\mathrm{C}}$, where $n$ is the number of stories; $T_{c}$ is the upper limit of the period of the constant spectral acceleration branch as shown in Fig. 4. The value of the fundamental period of vibration, $T$, is determined (ECP-201 2012) [28] as follows:

$$
T=C_{t} \times H^{3 / 4}
$$

Where $C_{t}$ is a factor determined according to the structural system and building material and equal to 0.075 in the case of MRF buildings; $H$ is the height of the building $(m)$ in meters. 


\subsection{Response spectrum (RS) method}

The response spectrum method (RS) is an approach to finding earthquake response structures using waves or vibrational mode shapes [7]. A response spectrum is defined as the maximum response (displacement, velocity or acceleration) of all possible SDOF oscillators, which can be described by their natural frequency and damping coefficient, natural period; it can be derived by analyzing a series of Single Degree-Of-Freedom (SDOF) systems. The quantities typically plotted are the Spectral Pseudo-Acceleration, Spectral Pseudo-Velocity, and Spectral Displacement, which are interrelated through the familiar expressions [34]. The modal response spectrum analysis is applicable for all types of buildings, while the equivalent lateral force method of analysis has many restrictions on its use due to the fear that it would provide un-conservative results in certain conditions; however, in spite of this disadvantage, the method is still widely used due to its ease of application [35]. Response spectrum analysis includes sufficient modes of vibration to capture participation of at least $90 \%$ of the structure's mass in all directions [36]. Many codes recognize that the period of vibration from the simplified period height equation is more realistic, having been directly obtained from the measured periods of vibration of buildings subject to earthquake ground motions, but that when higher modes are important in tall and/or irregular structures. The modal response spectrum method gives a more realistic profile of the lateral forces. Hence, these codes (ASCE 2005, NBCC 2005, ECP$2012008 \&$ 2012) $[27,28,37,38]$ require the designer to check whether the modal base shear force is less than $85 \%$ of the base shear force from the equivalent static force method. If this is the case then the modal forces, but not the drifts, should be multiplied by $0.85 V / V_{t}$ where $V$ is the base shear from the lateral force method and $V_{t}$ is the base shear from the required modal combination. Moreover, for the structures with extreme irregularities in layouts of mass and stiffness, the torsion effects under seismic action in two directions should be considered simultaneously [39].

\section{Target multi-story MRF buildings}

\subsection{Physical model of studied building}

During the past two decades, the building environment in Egypt had extensively utilized medium-rise R.C. buildings. These buildings are built with different configurations and structural systems with varying stiffness parameters that have great influence on their seismic behavior. Plan asymmetric buildings are very susceptible to earthquake induced damage due to lateral torsional coupling, and the corners of these systems suffer heavy damage during earthquakes. Therefore, it is important to investigate the seismic behavior of an asymmetric plan building. The building structural elements have been designed according to Egyptian code of practice (ECP-201, 2008) [27] under static loads with the assumption of un-cracked sections for beam and slabs in the analysis. Dead loads include the self-weight of the structure: a typical floor cover of $0.15 \mathrm{t} / \mathrm{m}^{2} ; 0.35 \mathrm{t} / \mathrm{m}^{2}$ at roof including required isolation; $0.15 \mathrm{t} / \mathrm{m}^{2}$ partitions (walls) load distributed as equivalent area load at typical floor. A live load of $0.25 \mathrm{t} / \mathrm{m}^{2}$ is considered at typical floor and $0.10 \mathrm{t} / \mathrm{m}^{2}$ at roof. Furthermore, a total seismic mass including Dead loads (DL) plus 50\% of live load (LL) is considered. Semi-ductile moment resisting frame system is considered to carry the seismic load, therefore the response modification factor $\mathrm{R}=5$. The seismic design has been carried out with assumption of: Soil class ' $\mathrm{C}$ ' as per referring to dense/stiff soil; Importance factor is equal to 1.0 ; Seismic zone factor $=0.15 \mathrm{~g}$, and the shape of the 
spectrum is type (1) as per Egyptian zoning system with a design ground acceleration, associated with the code reference probability of exceedance of $10 \%$ in 50 years. For Response Spectrum Method, Square Root of Sum of Squares (SSRS) is used as Directional Combination Method, complete quadratic combination (CQC) for Modal Combination Method. Response Function factors $C_{a}=0.18$ and $C_{v}=0.25$ is considered according to UBC 97 classification for soil class ' $C$ ', Use Ritz vector and number of mode shape to achieve more than $\mathbf{9 0} \%$ from mass participation as response spectra condition, Damping ratio $=5 \%$ as for $\mathrm{RC}$ moment resisting frame building.

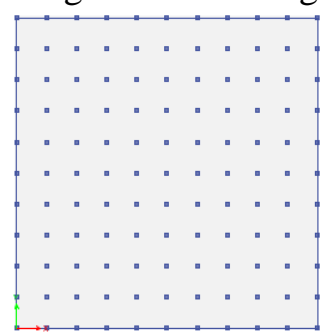

a) Plan of Reference regular/symmetric Model "RM"

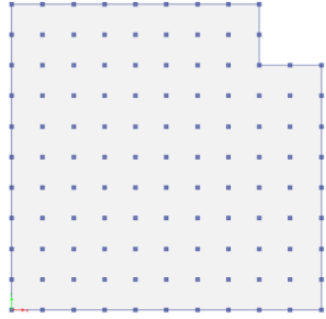

b) Model L1

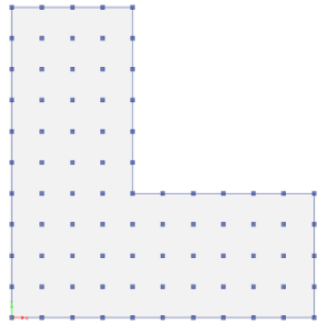

e) Model L4

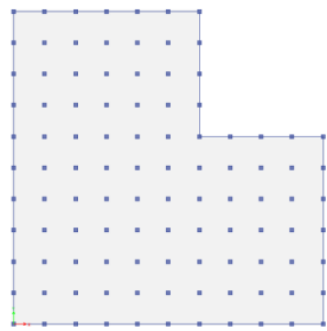

c) Model L2

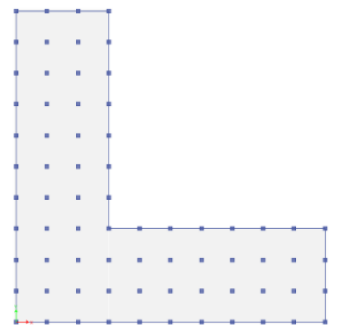

g) Model L5

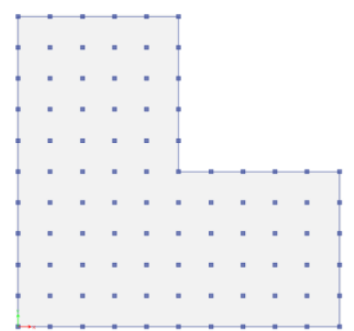

d) Model L3

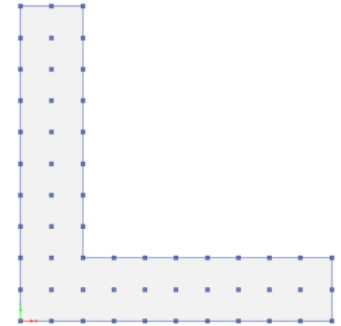

h) Model L6

Fig. 5. Reference regular model "RM" and irregular L-shaped models

\subsection{Mathematical model and finite element solution}

Mathematical modeling and finite element methods are introduced for the seismic analysis of the MRF buildings. Where the seismic demands of six horizontal irregularity L-shaped in plan buildings (Li models) that built through gradual reduction in plan area (by taking chunks from initial regular shape) are investigated and compared to that of square regular building as reference model (RM model) as shown in Fig 5. Each model Consist of ten equal bays in both directions, each bay has a width of $5 \mathrm{~m}$. All models have nine stories with total height of $28 \mathrm{~m}$ (4 $\mathrm{m}$ for ground floor and $3 \mathrm{~m}$ for the typical floor). Three-dimensional model are be constructed by ETABS software [40] for analysis and design of structural elements. In addition, SAFE software [41] is used to Design and Check of long-term Deflection and Punching for Slabs. The materials used in the design are C400 for concrete and steel types St40/60 for longitudinal rebar and Steel 
St24/35 for transverse rebar (stirrups). The minimum safe column cross section under static and dynamic loads is designed to satisfy the Eurocodes and Egyptian codes requirements (EC8 2004, ECP-203 2007, ECP-201 2012) [28,30,42]. Beams of 25 x $60 \mathrm{~cm}$ dimensions are used as marginal beam for flat slab system, flat slab thicknesses of $16 \mathrm{~cm}$ are determined considering the semi-rigid diaphragm action to confirm actual simulation for slab regarding deformation in addition to effective limitation due to gradual reduction that occurred for L-shaped models. Seismic analysis and design of reinforced concrete structures are performed based on linear response, however it is universally accepted that under severe earthquakes inelastic response and cracking is accepted. Therefore element properties should reflect this condition and inertias of beams and columns should be reduced accordingly. The seismic design of studied building models is carried out according to Eurocodes and Egyptian codes that imply taking into account the effect of cracking while evaluating the stiffness of reinforced concrete elements, hence affect size of seismic forces and lateral displacements demands. A reduction in stiffness of structural members is according to ECP-201 (2012) [28] taking into account effect of cracking. The column design details are given in Table $\mathbf{1}$.

Table 1.

Columns Cross section over the buildings' height

\begin{tabular}{|c|c|c|c|c|c|}
\hline $\begin{array}{c}\text { Columns } \\
\text { Type }\end{array}$ & \multirow{2}{*}{$\begin{array}{c}\text { Dimensions } \\
(\mathrm{mm})\end{array}$} & Long. & \% of St from & \multicolumn{2}{|c|}{ Floor Level } \\
\cline { 5 - 6 } & Rebar & Conc. Dim. & From & To \\
\hline $\mathrm{C} 1$ & $400 \times 400$ & $16 \mathrm{~T} 22$ & 3.80 & Seventh & Roof \\
\hline $\mathrm{C} 2$ & $500 \times 500$ & $20 \mathrm{~T} 22$ & 3.04 & Fourth & Sixth \\
\hline $\mathrm{C} 3$ & $600 \times 600$ & $24 \mathrm{~T} 22$ & 2.53 & Ground & Third \\
\hline
\end{tabular}

Table 2.

Eccentricity due to geometric irregularity

\begin{tabular}{|c|c|c|c|c|c|c|c|}
\hline Model & RM & L1 & L2 & L3 & L4 & L5 & L6 \\
\hline Plan reduction as plan area \% & 0 & 4 & 16 & 25 & 36 & 49 & 64 \\
\hline Eccentricity as model length \% & 0.00 & 5.68 & 6.12 & 6.48 & 6.88 & 8.07 & 9.14 \\
\hline
\end{tabular}

\section{Numerical results and discussion}

The performance of irregular buildings under seismic effects is a problem unless precautionary measures are taken. Irregular buildings need better planning and precautions while planning for its seismic performance [43]. Buildings subjected to ground shaking simultaneously undergo lateral as well as torsional motions if their structural plans do not have mass and stiffness symmetry in two axes. Coupled lateral-torsional motions can also occur in nominally symmetric buildings - buildings with structural plans that have mass and stiffness symmetry in two axes - if ground shaking includes a torsional component or due to unforeseen conditions such as unbalanced load distributions or differences between actual and assumed mass and stiffness distributions. As a result of coupled lateral-torsional motions, the lateral forces experienced by various resisting elements would differ from those experienced by the same elements if the building had symmetric plan and hence responded only in planar vibrations. So the main objective of this study is to evaluate seismic behavior for irregular buildings with re-entrant corner in forms L-shaped buildings compared to the reference regular building model "RM". Table 
Momen M. M. Ahmed et al., Irregularity effects on the seismic performance of l-shaped ..........

2 introduces the eccentricity due to geometric irregularity that could be a measure index of the degree of lateral - torsional vibration coupling. Significant measured response demands are investigated: like codal and analytical vibration period, story drift ratio, lateral displacements, torsional irregularity ratio according to submitted national codes, torsional diaphragm rotation (the best indicator for torsional action), normalized base shear (in account of different area of models under study), demand curve (normalized base shear versus top displacement) and normalized overturning moment.

\subsection{Natural vibration analysis}

The period of vibration is a fundamental parameter in the force-based design of structures as it defines the spectral acceleration and thus the base shear force to which the building should be designed. This study takes a critical look at the way in which seismic design codes around the world have allowed the designer to estimate the period of vibration for use in both linear static and dynamic analysis. In most building design projects, empirical building period formulas are used to initiate the design process [44]. The fundamental period of vibration, $T$, is a function of the stiffness of the lateral load resisting system and the building mass. The fundamental period in ECP-201 (2008), $T$ is not influenced by the change of floorplan shape but depends only on the building height. Table 3 presents different fundamental periods, for the studied buildings as obtained from the structural analysis using finite element models and empirical expression in the ECP-201 (2012, 2008) and other international building codes. In both regular and L-shaped (irregular) buildings, the computed periods from empirical expressions are significantly shorter than those computed from structural models. The lateral or translational and torsional motions of the structure are coupled if the center of mass and resistance do not coincide. The usual approach may be reasonable even for such torsionally coupled buildings if the eccentricities of the center of story resistance with respect to the center of floor mass are small and the natural frequencies of the lower modes are well separated. It is rather obvious that if the eccentricities are large, lateral and torsional motions will be strongly coupled.

Table 3 shows the disparity between the fundamental period of vibration from empirical period-height equation from different codes and the period of vibration from Eigenvalue analysis of a bare frame model. The fundamental period estimated by the ECP201 empirical equation is underestimated plus does not regard floor-plan shape (for regular and L-shaped building same value) models; the fundamental period reaches $316 \%$ to $269 \%$ in models from regular and irregular respectively. Flexural stiffness of slabs is ignored in the conventional analysis of bare frame structures. However, in reality, the floor slabs may have some influence on the lateral response of the structures. Consequently, if the flexural stiffness of slabs in a frame system structure is totally ignored, the lateral stiffness of the global frames may be underestimated [45]. Fig. 6 shows the comparison between the codal and analytical fundamental vibration period; codal period calculated from conventional method regardless effective parameter which is building's dimension. Furthermore, floor plan shape had been assigned as a vital factor whereas the fundamental vibration period had been reduced by increasing the accidental irregularity while suffering from constancy for empirical (ECP-201 2012) [28], stated significant defect in the conventional calculation of vibration period which is considered themain parameter for lateral force procedure. 
JES, Assiut University, Faculty of Engineering, Vol. 44, No. 5, September 2016, pp. 513 - 536

Table 3.

Fundamental period of the reference Model and L-shaped buildings

\begin{tabular}{|c|c|c|c|c|c|c|c|c|c|c|}
\hline \multirow{2}{*}{\multicolumn{4}{|c|}{ PROCEDURES }} & \multicolumn{7}{|c|}{ Studied models } \\
\hline & & & & $R M$ & $L 1$ & $L 2$ & L3 & L4 & $L 5$ & L6 \\
\hline \multirow{5}{*}{\multicolumn{2}{|c|}{$\begin{array}{c}\text { 3D } \\
\text { Model } \\
\text { Natural } \\
\text { Vibration } \\
\text { Analysis }\end{array}$}} & \multicolumn{2}{|c|}{$1^{\text {st }}$ fundamental vibration mode shape, $T_{1}$} & 2.89 & 2.85 & 2.73 & 2.63 & 2.53 & 2.46 & 2.46 \\
\hline & & \multicolumn{2}{|c|}{ Modal direction Factor, Ux } & 0.70 & 0.50 & 0.50 & 0.49 & 0.47 & 0.39 & 0.28 \\
\hline & & \multicolumn{2}{|c|}{ Modal direction Factor, Uy } & 0.30 & 0.50 & 0.50 & 0.49 & 0.47 & 0.39 & 0.28 \\
\hline & & \multicolumn{2}{|c|}{ Modal direction Factor, $\mathrm{Rz}$} & 0.00 & 0.00 & 0.00 & 0.02 & 0.06 & 0.22 & 0.44 \\
\hline & & \multicolumn{2}{|c|}{$2^{\text {nd }}$ vibration mode - Torsional mode, $\mathrm{T}_{2}$} & N/A & 1.93 & 1.93 & 1.94 & 1.94 & 1.88 & 1.7 \\
\hline \multirow{9}{*}{ 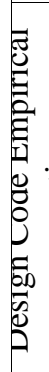 } & \multirow{9}{*}{\multicolumn{3}{|c|}{$\begin{array}{ll}\text { ECP-201 (2012\&2008) } & T=0.075 H^{0.75} \\
\text { ECP-201 (1993) } & T=0.1 N \\
\text { ASCE 7-05 } & T=0.028 H^{0.80} \\
\text { IBC (2003) } & T=0.073 H^{0.75} \\
\text { UBC (1997) } & T=0.049 H^{0.75} \\
\text { IS (2002) } & T=.09 H / \sqrt{D} \\
\text { ICC (2003) } & T=0.073 H^{0.75} \\
\text { NBCC (2004) }(2005) & T=0.075 H^{0.75} \\
\end{array}$}} & \multicolumn{7}{|c|}{0.913} \\
\hline & & & & \multicolumn{7}{|c|}{0.900} \\
\hline & & & & \multicolumn{7}{|c|}{1.047} \\
\hline & & & & \multicolumn{7}{|c|}{0.888} \\
\hline & & & & \multicolumn{7}{|c|}{0.596} \\
\hline & & & & \multicolumn{7}{|c|}{0.360} \\
\hline & & & & \multicolumn{7}{|c|}{0.864} \\
\hline & & & & \multicolumn{7}{|c|}{0.913} \\
\hline & & & & \multicolumn{7}{|c|}{0.608} \\
\hline
\end{tabular}

Note: $H$ is the building's height above the foundation level till highest floor level, $N$ is the number of the stories and $\mathrm{D}$ is the directional dimension of building under study.

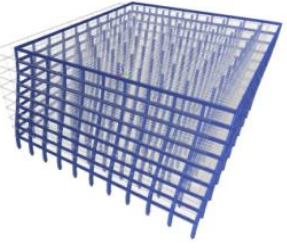

Model RM, $\mathrm{T}_{1}=2.89$

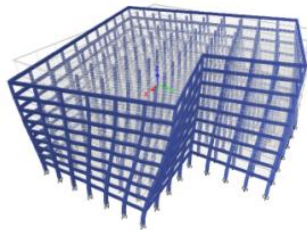

Model L2, $\mathrm{T}_{2}=1.93$

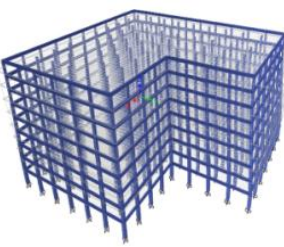

Model L2, $\mathrm{T}_{1}=2.73$

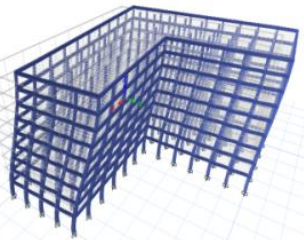

Model L4, $\mathrm{T}_{1}=2.53$

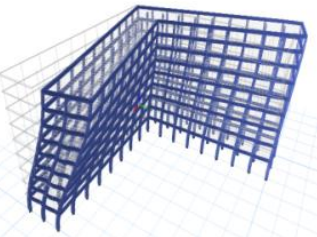

Model L6, $\mathrm{T}_{1}=2.46$

$1^{\text {st }}$ vibration mode shape

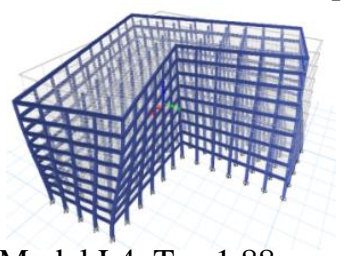

Model L4, $\mathrm{T}_{2}=1.88$

$2^{\text {nd }}$ vibration mode shape

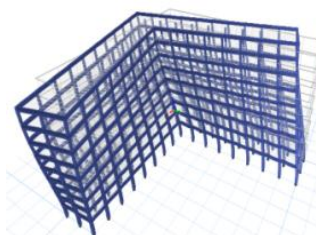

Model L6, $\mathrm{T}_{2}=1.7$

Fig. 6. Vibration mode shapes

\subsection{Global seismic response demands}

\subsubsection{Story drift ratio response}

Story drift ratio is the maximum relative displacement of each floor divided by the height of the same floor is an important parameter that has been evaluated. Lateral deflection and drift have three primary effects on a structure; the movement can affect the structural elements such as beams and columns; the movements can affect non-structural elements such as the windows and cladding, and the movements can affect adjacent structures. Without proper consideration during the design process, large deflections and 
Momen M. M. Ahmed et al., Irregularity effects on the seismic performance of l-shaped ..........

drifts can have adverse effects on structural elements, nonstructural elements, and adjacent structures [46]. The story drift ratio response demand is investigated for L-shaped irregular building models and compared to the reference regular building model. The story drift ratios over the building's height for different models are introduced in Figs $\mathbf{7}$ and $\mathbf{8}$.

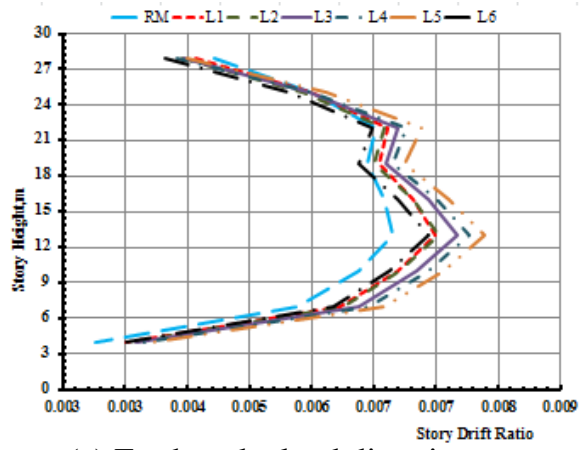

(a) Earthquake load direction

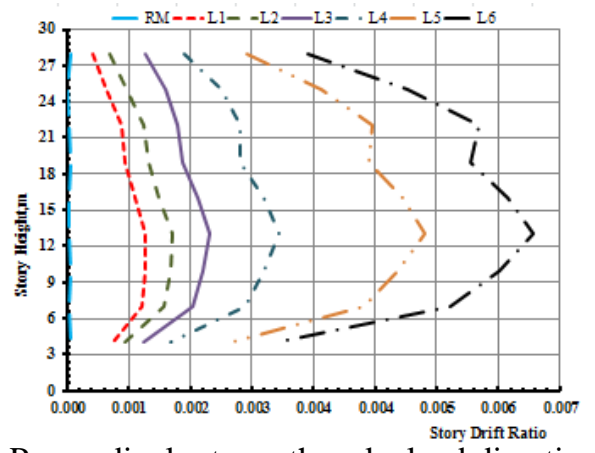

(b) Perpendicular to earthquake load direction

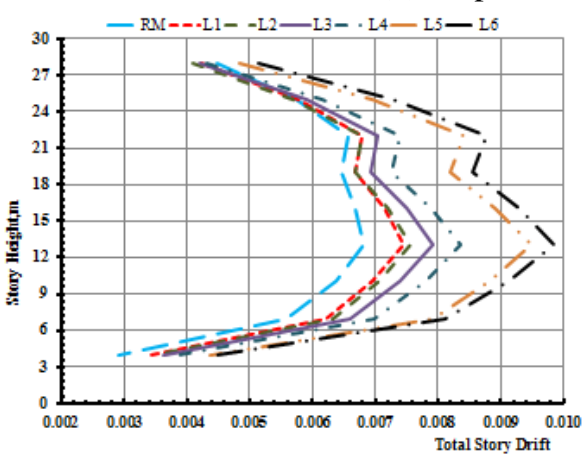

c) Total story drift Based on SSRS

Fig. 6. Story Drift Ratio responses for different models

Fig. 7(a) shows that story drift ratio is created at earthquake direction distribution of 9-story models increases gradually over building's height and reaches its maximum value in the $4^{\text {th }}$ story level then decreases at the higher levels. The story drift response increase at the degree of building configuration irregularity increases from RM model to L5 model then decreases at L6 Model. The story drift response gets it maximum value for Model L5 and reaches 0.008 that is $17.5 \%$ over, compared to that of reference model RM. The story drift responses are 0.0074 (8\%), 0.0074 (8.8\%), 0.0076 (12.2\%), 0.0078 (14.5\%), 0.008 (17.5\%), 0.0073 (6\%) for models L1 to Model L6 respectively that confirm the effect of floor shape irregularity effect.

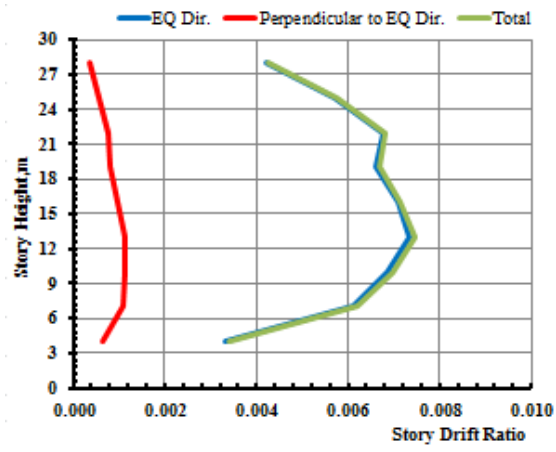

(a) L1

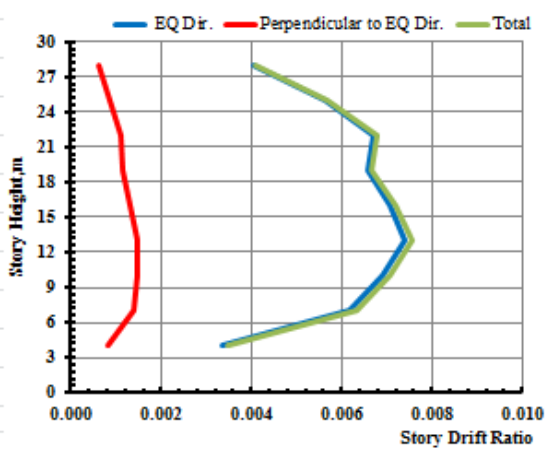

(b) L2 


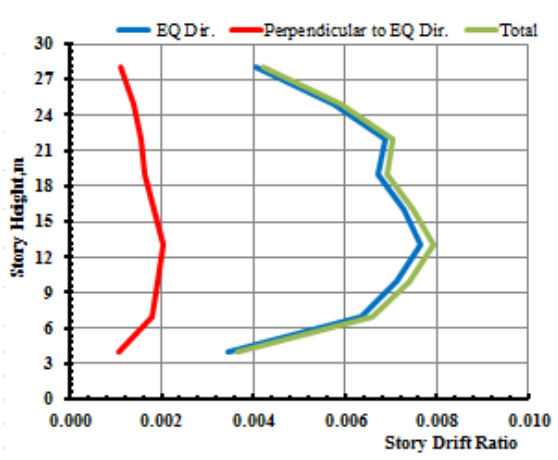

(c) L3

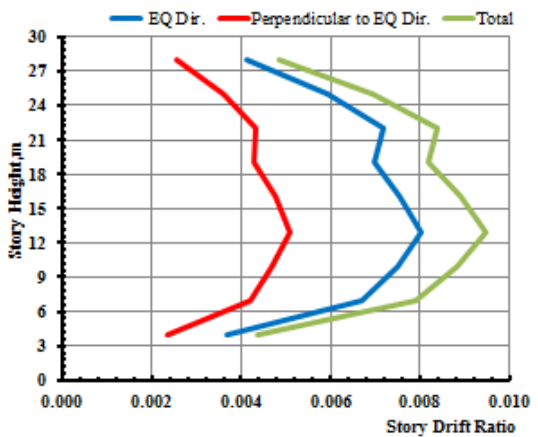

(e) L5

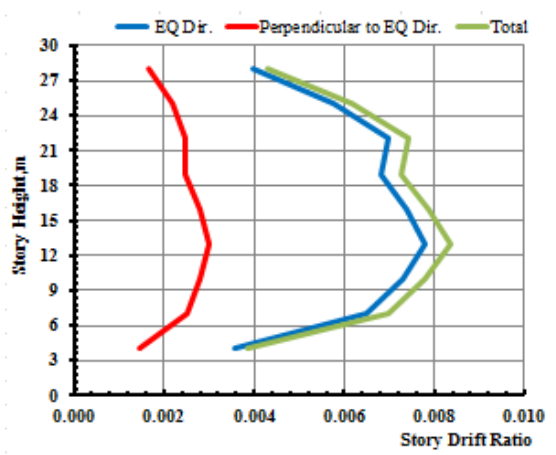

(d) L4

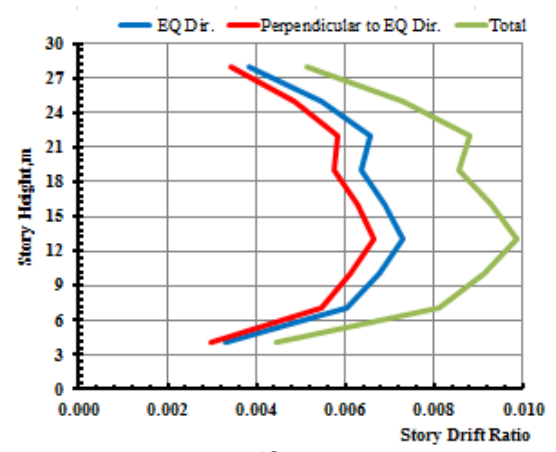

(f) L6

Fig. 7. Effect of lateral torsional vibration coupling in the Story drift ratio for L-shaped models

Fig. 7(b) shows the story drift ratio response distribution along models' height that is additionally produced in the perpendicular to earthquake direction. Story drift response that is produced in the perpendicular direction to earthquake excitation, increases gradually as eccentricity increases, and reach to a maximum value 0.0063 for L6 model, which has maximum eccentricity and the story drift ratio significantly increases with gradually reduce in model due to lateral-torsional vibration coupling. Fig. 7(c) shows that total story drift ratio distribution over models' height; the total story drift is calculation based on SSRS approach of story drift response in the excitation direction and the perpendicular direction. The total story drift differ from unidirectional story drift that is pretended from direct analysis for seismic response; the irregularity floor shape effects on the total story drift ratios reach 135.3, 118.4, 107.1, 103.4, 102.0, 101.1\% for L6, L5, L4, L3, L2, L1 of unidirectional story drift ratio response, respectively.

Figs. 8 (a, b, c, d, e, f) show that unidirectional story drift ratio response in both the earthquake load direction and perpendicular direction for different L-shaped models plus total story drift ratio response distribution along the height independently for each model. The figure illustrates that the developed story drift demand in the perpendicular direction to earthquake load is significantly increased with configuration irregularity, hence a detrimental torsion action threaten sustainability of the building appealing unprotected functionality. Story drift ratio perpendicular to earthquake direction increases with eccentricity increases, not only this but also become closely equal to story drift ratio in the direction of earthquake load. Hence, the developed story drift ratio due to torsion action assaulting in the L-shaped model dignify the worth of research in an irregular floor plan that different codes retire dealing with this type providing unavailing restrictions. 
Momen M. M. Ahmed et al., Irregularity effects on the seismic performance of $l$-shaped ..........

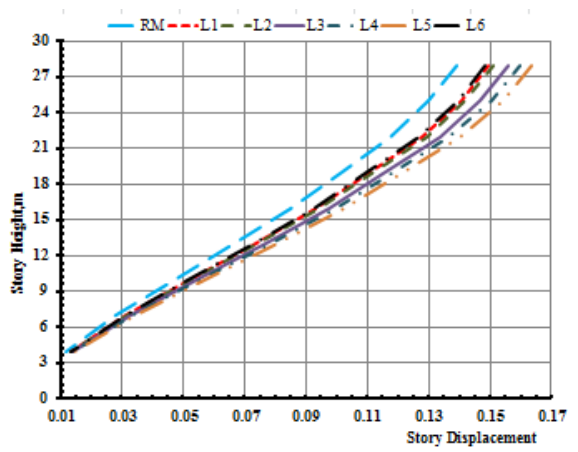

(a) Earthquake load direction

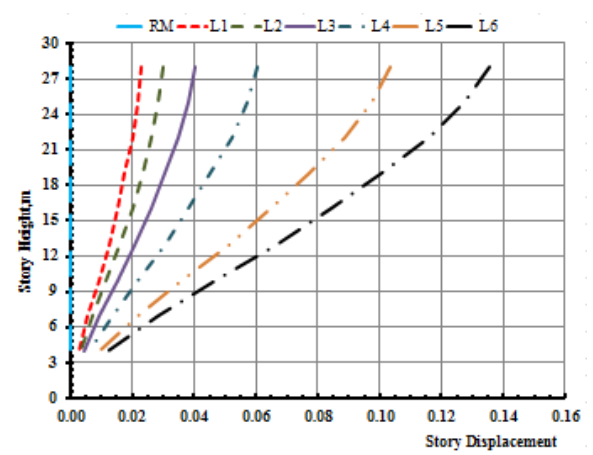

(b) Perpendicular to earthquake load direction

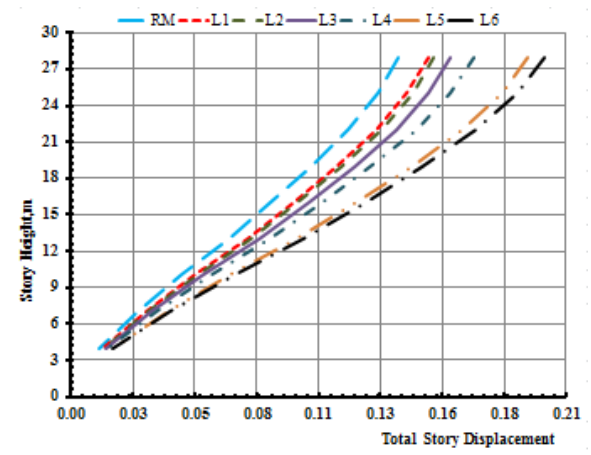

c) Total story displacment based on SSRS

Fig. 8. Story displacmentresponses for different models

\subsubsection{Lateral displacement response}

The horizontal displacement of tall buildings is one of the most serious issues in tall building design, relating to the dynamic characteristics of the building during earthquake [47]. The amplification of lateral deformations could change the performance level of the building frames. In addition, the lateral deflection and drift could affect the entire building performance and design of nonstructural elements [12]. The nonstructural elements should be designed to allow the expected movement of the structural system [46]. Thus, to evaluate the realistic performance level of a structure, a comprehensive dynamic analysis should consider the effects of floor-shape irregularity on the lateral displacement demands. The story lateral displacements over the buildings' height for different models are introduced in Figs 9 and 10.

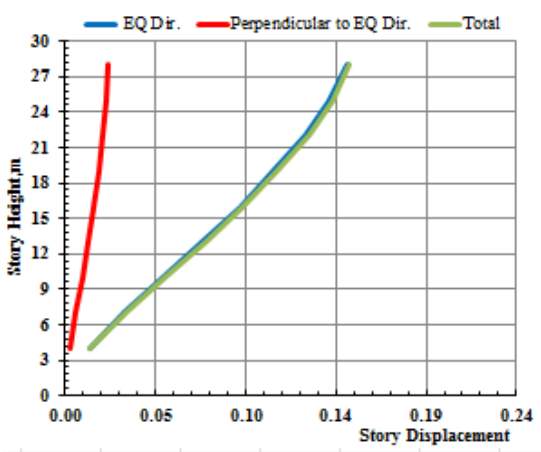

(a) L1

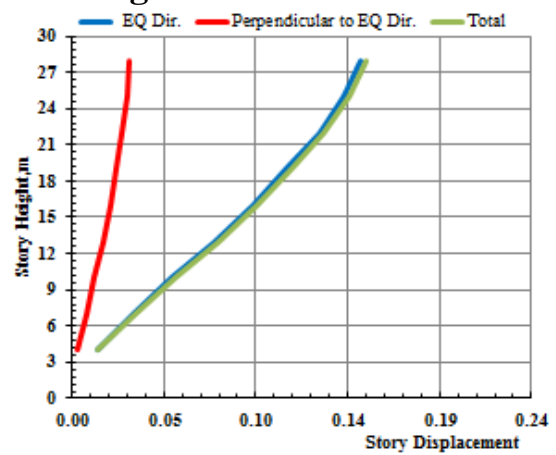

(b) L2 


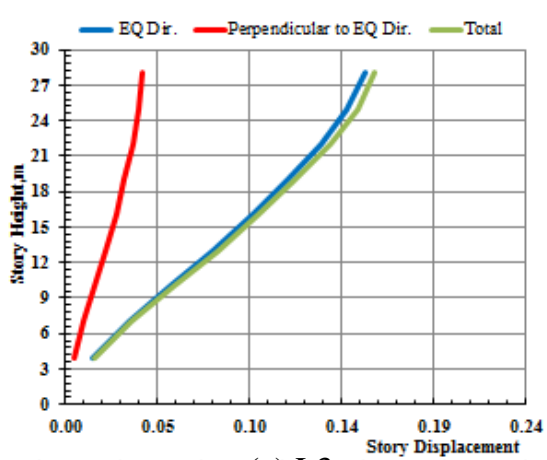

(c) L3

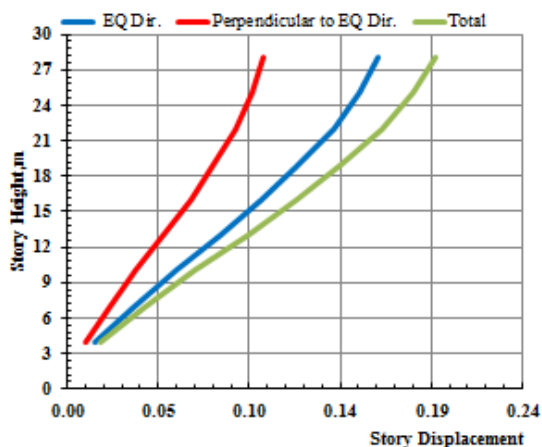

(e) L5

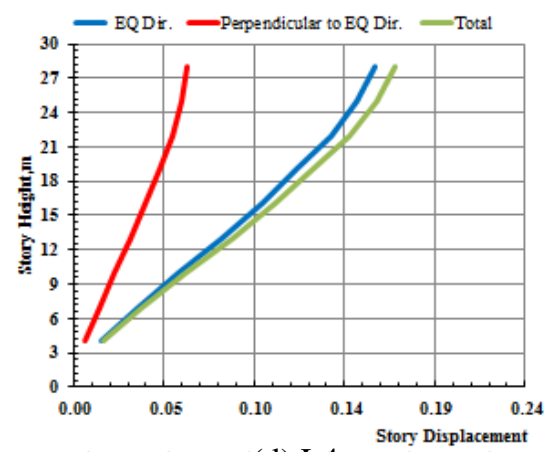

(d) L4

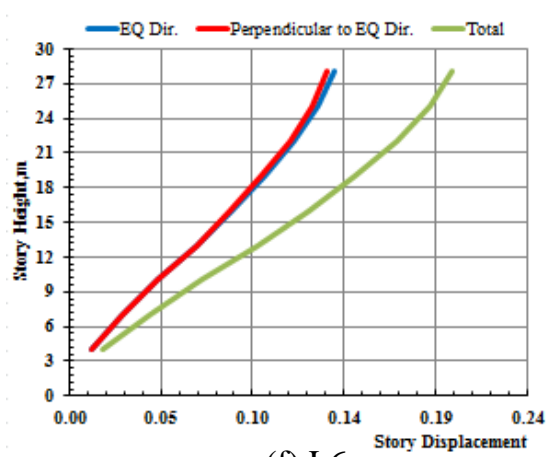

(f) L6

Fig. 9. Effect of lateral torsional vibration coupling in the Story dispalcment for L-shaped models

Fig. 9(a) shows that maximum story displacement distribution along models heights at earthquake direction. Model L5 displays the greatest top displacement response of equal $0.164 \mathrm{~m}$, which is $117.8 \%$ of that RM model. The lateral displacement response demands increase with configuration regularity, have values of $0.15 \mathrm{~m}(107.7 \%), 0.151 \mathrm{~m}(108.6 \%)$, $0.156 m$ (112.3\%), 0.160m (114\%), 0.164m, (117.8\%) for models L1 to L5 models, respectively. The story displacement response demands distribution over the models' height that are developed in the perpendicular direction to earthquake load is shown in Fig. 9 (b), where the story displacement response demand increases gradually with configuration irregularity of the building model due to lateral- torsional vibration coupling. The vibration coupling gets its maximum effects on the displacement demands of $0.136 \mathrm{~m}$ for L6 model, which closely equal lateral displacement in earthquake direction. The seismic performance level could be significantly changed due to configuration irregularity and eccentricity, hence leads to additional displacement demands compared to the reference model. Fig. 9 (c) shows that maximum total story displacement based on SSRS of both bi-directional responses, where the maximum total lateral displacement are 0.200 , $0.193,0.170,0.161,0.153,0.151$ and $0.139 m$ for L6, L5, L4, L3, L2, L1 and RM respectively. Total lateral displacement response develops through the incremental eccentricity striking structural sustainability with destitute codal calculation depending only in force demand and direct (RS) analysis checking only lateral displacement in earthquake direction regardless actual totally lateral displacement could be amplified.

Fig. 10 illustrate that the story displacement response demand in the perpendicular direction to earthquake load is significantly developed with gradually increase of lateraltorsional vibration coupling, hence results in a detrimental torsion action threaten and 
Momen M. M. Ahmed et al., Irregularity effects on the seismic performance of l-shaped .........

tolerable levels of risk for the building. The story displacement in the perpendicular direction to earthquake load grows with the development of the eccentricity in L-shaped models become closely equal to story displacement in the same earthquake direction as the L6 model. The lateral displacement demand has changed due to vibration coupling effect that could cause and amplification seismic response demand.

\subsubsection{Torsional irregularity ratio}

Torsional irregularity is one of the most important factors, which causes severe damage to the building structures. A large number of studies exist which investigate various aspects of torsional irregularity including geometric asymmetry [48,49]. Torsional Irregularity Ratio is defined to exist where the maximum story drift, computed including accidental torsion, at the end of the structure transverse to an axis is more than 1.2 times the average of the story drift at the end of the structure [37]. Moreover, torsional irregularity ratio is an analytical index derived based on generic response characteristics, and accounts for the multi-directionality of earthquake motion as well as the asymmetry of the structure; hence, it captures the true three-dimensional inelastic effects that govern the response of building structures whereas it recognizes the differential deformation in plan, hence ability of vertical resisting element to withstand anticipated lateral forces. The Torsional irregularity ratio $\left(\mu_{t}\right)$ is defined as indication.

Torsional Irregularity ratio $\quad \mu_{t}=\frac{\Delta_{2}}{\Delta_{a}}$ and $\Delta_{a}=\frac{\Delta_{1}+\Delta_{2}}{2}$

Where $\Delta_{2}$ is the maximum story drift and $\Delta_{a}$ is the average drift of the story; the criterion for torsional irregularity of the structures is approximately in the same form as shown in Fig. 11.

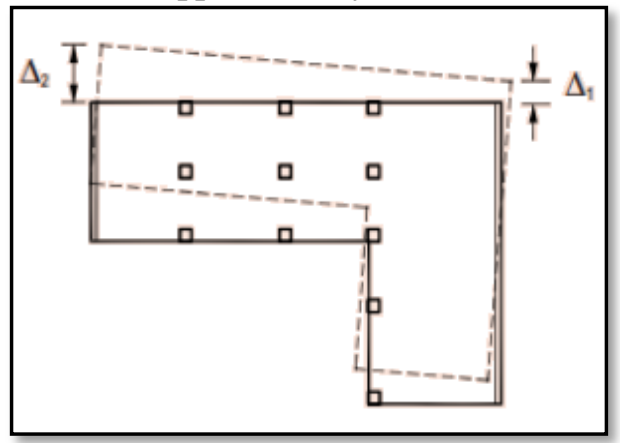

Fig. 10. Sketch for Torsional irregularity ratio

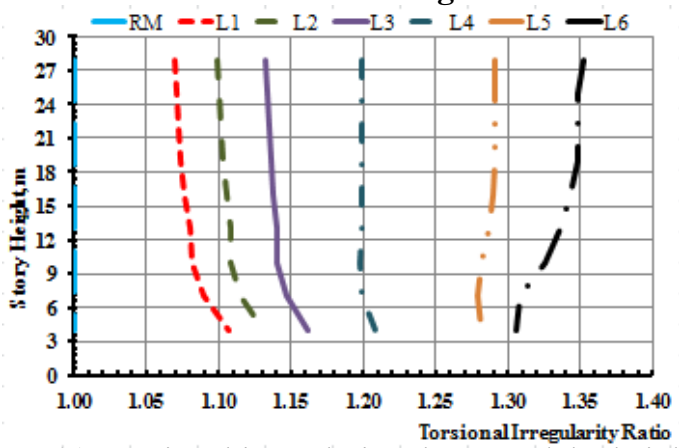

(a) Torsional irregularity along models' height

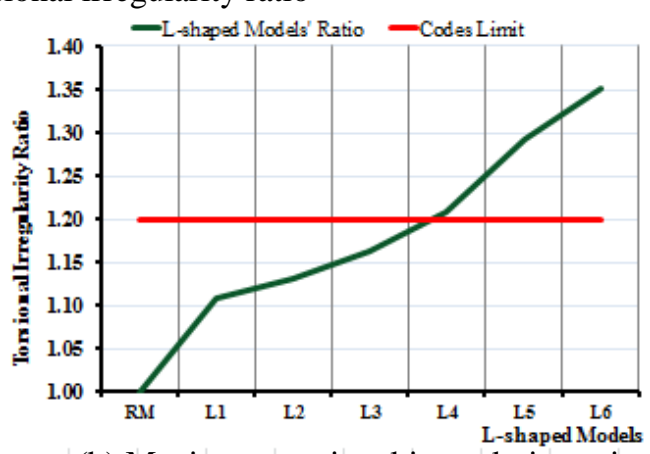

(b) Maximum torsional irregularity ratio

Fig. 11. Torsional irregularity ratio for different models. 
Fig. 12(a) shows the torsional irregularity ratio for L-shaped building along models' height; torsional irregularity ratio is slightly changed over the building model heights, but grows up with the increase of model eccentricity. For models with small eccentricity, the lower stories exhibit large torsional deformation more than upper stories in contrary to models with large eccentricity models display more torsional deformation at upper stories. Fig. 12 (b) shows the maximum torsional irregularity ratio for L-shaped building models, where the maximum torsional irregularity ratio for L-shaped models L1, L2, L3, L4, L5 and L6 are 1.11, 1.13, 1.16, 1.21, 1.29 and 1.35 respectively, while the torsional irregularity ratio limit from different codes (IS 2002, ASCE 2010) [37,50] is 1.2. When the ratio exceeds this value means that building is affected by differential deformation in plan further significantly affect the seismic performance level for building, therefore the design procedure for resisting element should be carefully formulated to reduce this torsional deformation.

\subsubsection{Torsional diaphragm rotation}

The torsional seismic effects caused by the irregularity of plan layout of building structures have been emphasized for seismic design in many codes [51] but the effect of this detrimental action causes twisting the building accompanying translation displacement for building with complex seismic configuration. Torsional diaphragm rotation is considered significant parameter to evaluate torsion moment plus probability of local failure for outer element threatening the robustness of a structure that is highly dependent on the performance of the diaphragms [52]. The floor system that experiences twisting due to differential movement of slab edges undergoes in-plane bending. The relative stiffness of the horizontal to vertical structural systems affects the torsional resistance of the frames and the in-plane rotation of the slabs [53]. A rotation of the slab system is assumed to take place at the center of the frame axis. The relationship for rotation $\theta_{\mathrm{f}}$ about the center, the anticipated frame moment $\mathrm{M}_{\mathrm{f}}$ and the stiffness coefficient $\mathrm{K}_{\mathrm{f}}$ is then determined for a unit rotation as follows:

$$
\mathrm{M}_{\mathrm{f}}=\mathrm{K}_{\mathrm{f} \cdot} \theta_{\mathrm{f}}
$$

Fig. 13(a) shows the torsional diaphragm rotation for L-shaped building over models' height; with the detrimental increase in eccentricity for models, the torsional response demand will be more head strong action proceeding influence in torsional diaphragm rotation for L-shaped models. The torsional diaphragm rotation changes through the height of the structure reaching the maximum value at the top level of models. Fig. 13(b) shows the maximum torsional rotation response demand for L-shaped building models; through which, maximum torsional diaphragm rotation for L-shaped models L1, L2, L3, L4, L5 and L6 are 0.0008, 0.0011, 0.0014, 0.0020, 0.0026 and $0.0030 \mathrm{rad}$ respectively.

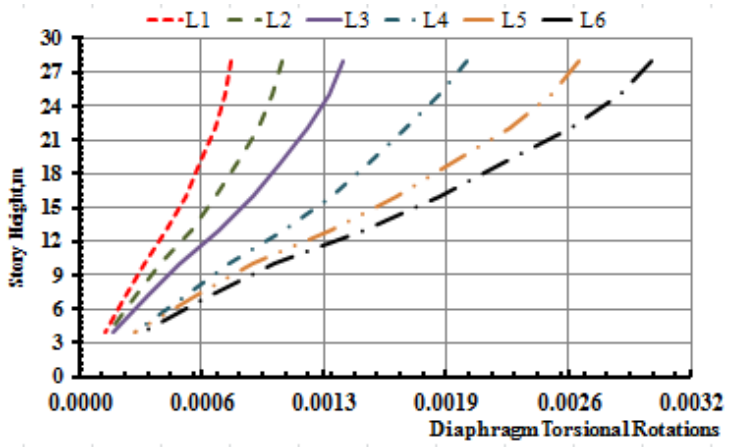

(a) Torsional rotation over models' height

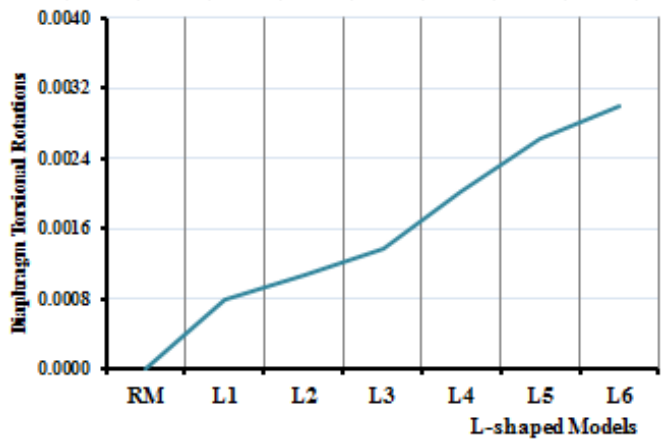

(b) Maximum torsional rotation

Fig. 12. DiaphragmTorsionalrotation response 
Momen M. M. Ahmed et al., Irregularity effects on the seismic performance of l-shaped .........

\subsubsection{Normalized base shear}

Normalized shear force presents shear force response demand at base as ratio to building's weight $\left(\mathrm{V}_{\mathrm{B}} / \mathrm{VW}\right)$; this parameter allows accurate comparison between buildings which accumulate different areas with different lumped masses. The successful comparison between regular reference model RM and L-shaped models in this manner equip real simulation for shear force is demanded according to seismic response for models.

Fig. 14(a) shows that normalized base shear force for each model in the earthquake loading direction, perpendicular direction to earthquake loading and total value. The total base shear significantly increases with gradually increasing in eccentricity between the center of mass and the center of rigidity whereas regular model display the lowest shear demand of $4.62 \%$ and with development of eccentricity by L-shaped models, the values are $4.62,4.69,4.87,5.05,5.52$ and $6.38 \%$ for L1, L2, L3, L4, L5 and L6 respectively. The additional shear force developed in the perpendicular direction to earthquake direction could violate the safe design for resisting elements; the developed shear force in the perpendicular direction could reach $0.08,0.38,1.27,1.71,2.59$ and $3.83 \%$ of the building weight for L1, L2, L3, L4, L5 and L6 respectively. These effects result from lateral torsional coupling action that may cause disastrous effect for lateral load resisting element. Fig. 14(b) shows Accidental angle for base shear force generated from lateral-torsional coupling action due to significant development in eccentricity for L-shaped buildings. The regular model has fully unidirectional horizontal force response but the accidental angle of bidirectional base shear force response for L-shaped models record 0.98, 4.52, 15.12, 17.80, 28.00, 36.85 rad respectively for L1, L2, L3, L4, L5 and L6 models.

The demand curve is considered a representation of the earthquake ground motion or shaking that the building is subjected to Also, demand is represented by an estimation of the displacements or deformations that the structure is expected to undergo. This is in contrast to conventional, linear elastic analysis procedures in which demand is represented by prescribed lateral forces applied to the structure [54]. Demand curve presents the relationship between base shear force subjected due to ground shaking and the produced lateral top displacement, in which the preliminary step had been done to evaluate the real seismic performance of buildings. The acquired results from normalized base shear and lateral top displacement relationship have been significantly noted in Table $\mathbf{4}$ containing demand curve for models under investigation.

Table 4.

Normalize base shear versus Top displacement

\begin{tabular}{|c|c|c|c|c|c|c|c|}
\hline Models & RM & L1 & L2 & L3 & L4 & L5 & L6 \\
\hline Normalized Base Shear $\left(\mathrm{V}_{\mathrm{B}} / \Sigma \mathrm{W}\right)$ & 4.46 & 4.64 & 4.69 & 4.87 & 5.05 & 5.52 & 6.38 \\
\hline Top Displacement, $\mathrm{m}$ & 0.139 & 0.151 & 0.154 & 0.161 & 0.171 & 0.194 & 0.201 \\
\hline
\end{tabular}

5.2.6. Codal and analytical normalized base shear

To better understand the seismic performance of a typical MRF buildings incorporating floor plan irregularity in a form of L-shaped, the seismic response of the structures in terms of the base shear according to Codal (ESL) and Analytical (RS) methods are selected for comparison as effective response parameter of interested. Fig. 15 shows the normalized base shear response $\left(V_{B} / \Sigma W\right)$ for regular reference and L-shaped models using ESL and RS methods. The calculated normalized base shear from conventional force method (ESL) is slightly affected by floor shape irregularity, on the contrary, significant rate of change in 
total normalized base shear developed from bidirectional effects regarding lateral-torsional coupling impact of the irregular configuration.

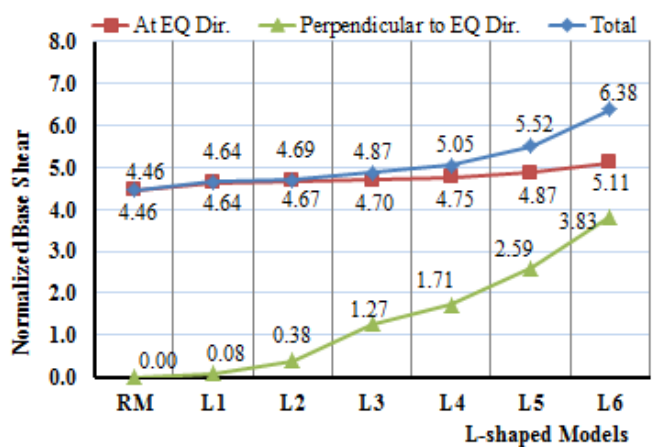

(a) Normalized base shear

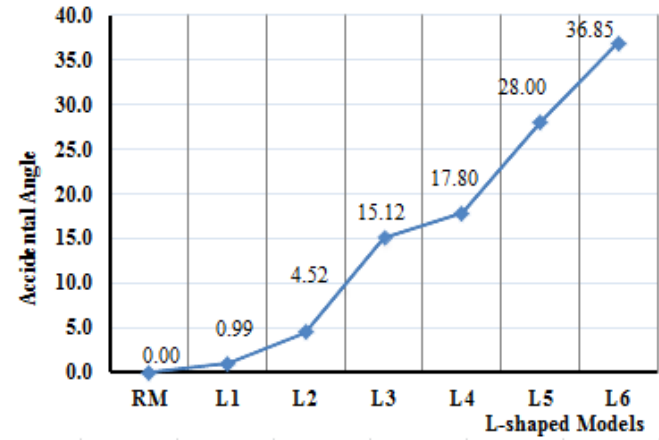

(b) Accidental angle

Fig. 13. Normalized base shear and its accidental angle

\subsubsection{Normalized overturning moment}

Normalized overturning moment presents bending moment response demand at base with respect to multiplication building's weight by its height equals $\left(\mathrm{M}_{\mathrm{B}} / \Sigma \mathrm{W} . \mathrm{H}\right)$; this parameter allows accurate comparison between buildings which accumulate different areas and lumped masses. The successful comparison between regular reference model and L-shaped models equip real simulation for the overturning moment demand according to seismic response for models. Fig. 16 shows the normalized overturning moment that is created at foundation level for each model in the earthquake loading direction, perpendicular direction to earthquake loading and total value. The overturning moment significantly increases with gradually increasing in eccentricity due to configuration irregularity, whereas regular model demand shows the lowest value 2.79. The value bending moment demands increase with the development of eccentricity by L-shaped models, their values are 2.79, 2.88, 3.02, 3.09, 3.38 and 3.98 for L1, L2, L3, L4, L5 and L6 respectively. The seismic normalized overturning moment response exchanges safe design for resisting element to unsafe element suffering from the additional force is progressed perpendicular to earthquake direction from torsion action cause adisastrous effect for lateral load resisting element.

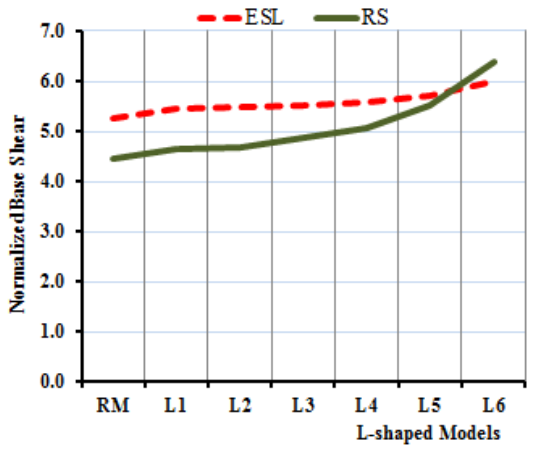

Fig. 14. Codal and Analytical normalized base shear

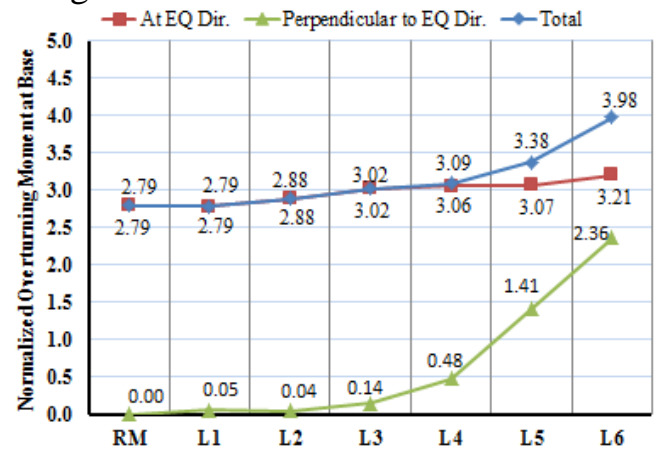

Fig. 15. Normalize overturning moment

\section{Summary and conclusion}

Seismic torsional response has been a principal cause of structural failure in every major earthquake. There are numerous observations of damages caused by excessive torsional response in buildings, bridges, and lifeline structures. The torsion-induced failures have been 
Momen M. M. Ahmed et al., Irregularity effects on the seismic performance of l-shaped ..........

especially catastrophic for multi-story buildings because torsional response changes the uniform translational seismic floor displacements and causes concentration of demand in elements at the perimeter of the building. This often leads to failure of the over-loaded elements, which in turn initiates progressive collapse of the building. Irregular structures are more used in new architectural design. In these structures the torsion phenomenon can induce detrimental stresses especially in the case of a seismic motion. The seismic codes try to take into account the torsion effect during modeling; however it is difficult to assess all the parameters that affect the behavior of this kind of structures.

This study aims to introduce a comprehension meaningful guideline for seismic design of irregular building with re-entrant corner in forms of L-shaped floorplan incorporating the effect of horizontal irregular configuration under moderate seismic zone for moderate rise reinforced concrete buildings. Mathematical models for the completed regular and irregular building are developed using ETABS software to determine the seismic response demands. The evaluation of L-shaped buildings is performed through comparison with regular reference model. The models are used to evaluate the effects of plan irregularity (distinguished by L-shape plan) on the maximum base shear force, overturning moment, torsional action and lateral displacement for the MRF multi-story buildings. The influence of the configuration irregularity effects on the seismic behavior of building structures is investigated. Two types of buildings are considered, one symmetrical reference model and the other asymmetrical L-shaped building models in terms of configuration irregularity, where the seismic performance of re-entrant corner buildings as irregular plan configuration are compared to that of reference building model (regular configuration). In this study, assimilation of seismic behavior for irregular buildings with re-entrant corner by taking gradually chunks from initial regular shape by specific ratio constituted L-shaped buildings under moderate seismic zone for moderate rise reinforced concrete buildings using the Equivalent Static Load (ESL) and Response Spectrum (RS) analysis techniques, which are adopted in the Egyptian code for loads and forces (ECP-201; 2008, 2012 and EC 8 ; 2004). The main finding results of the study are summarized as follows:

For regular and L-shaped Buildings, The empirical expression for calculating the fundamental period of vibration using ECP-201 (2008, 2012) and all other used codes underestimates the actual fundamental period compared to the mathematical models. Moreover, as the floor-plan irregularity increases, the fundamental period of the structural model decreases, this means that the fundamental period is not only a function of building height as conventional method presented but accumulates a function of building's shape. The degree of lateral-torsional coupling of the vibration modes significantly increases with the configuration irregularity of L-shaped models.

Total story drift responses ratio increases as the floor plan irregularity gradually increase. Story drift response along the height of the building shows that the middle stories are more affected than Lower and upper stories. Aside from that additional story drift is developed in the perpendicular direction to the earthquake loading. The total story lateral displacement response increases as the floor shape irregularity raise creating harmful act in external non-structural elements other than lateral displacement perpendicular to the earthquake direction articulated cloudless effect of floor-shape irregularity neglected by conventional method lessening pursued functionality and safety. The total story drift differ from unidirectional story drift that is pretended from direct analysis for seismic response; 
the irregularity floor shape effects on the total story drift ratios reach more than $135 \%$ of unidirectional story drift ratio response.

The lateral shear force demands in vertical resisting elements located on the periphery of the structure are significantly increased in comparison with the corresponding values for a symmetric building. It is concluded that for particular ranges of the key parameters defining the structural system, torsional coupling induces a significant amplification of earthquake forces which should be accounted for in their design. The total base shear significantly increases with gradually increasing in eccentricity between the center of mass and the center of rigidity whereas regular model display the lowest shear demand of $4.62 \%$ and with development of eccentricity by L-shaped models, the values are 4.62, 4.69, 4.87, 5.05, 5.52 and $6.38 \%$ for L1, L2, L3, L4, L5 and L6 respectively.

The total overturning moment response located at foundation level calculated from seismic analysis for L-shaped models are clear exemplified in effect of irregularity for plan shape obsolete from ordinary structural designers using empirical equation, poor configuration of structural components wrecked the building's stability behind the senses and might be need of special dealing for seismic analysis. The overturning moment significantly increases with gradually increasing in eccentricity due to configuration irregularity, whereas regular model demand shows the lowest value 2.79 . The value bending moment demands increase with the development of eccentricity by L-shaped models, their values are 2.79, 2.88, 3.02, 3.09, 3.38 and 3.98 for L1, L2, L3, L4, L5 and L6 respectively. The seismic normalized overturning moment response exchanges safe design for resisting element to unsafe element suffering from the additional force is progressed perpendicular to earthquake direction from torsion action cause adisastrous effect for lateral load resisting element.

The analysis demonstrates that plan irregularity has a significant effect on the seismic response of buildings compared to the typical assumption in which floor-plan irregularity would be neglected in conventional design national codes. When the floor is not stiff enough as the case of L-shaped Floor, the dynamic response of the structure will be influenced significantly by the distribution of the lateral forces at its level because of the lateral differential deformation that happened plus torsion action which may cause local damage to the outer columns threaten the building's robustness during the earthquake. When the structure is designed as regular configuration without evaluating the actual seismic performance, the dynamic response of the structure will be different from the theoretically calculated from national codes resulting significant modification in sustainability. It is concluded that the floor shape plays a considerable role in the seismic behavior of moderate rise MRF building including a substantial increase in the lateral deflections and inter-story drifts and changing the performance level of the structures and pursued functionality. Thus, considering plan irregularity effects in the seismic design, particularly when floor shape is mostly used in vital buildings is essential. If the irregularity is not taken into account in dynamic analysis and design; the accuracy in assessing the structural safety, facing earthquakes, could not be reliable. The conventional design procedures excluding the horizontal irregularity may not be adequate to guarantee the structural safety of irregular moment resisting building.

\section{REFERENCES}

[1] Monish S., S. Karuna (2015). "A study on seismic performance of high rise irregular RC framed buildings." International Journal of Research in Engineering and Technology (IJRET) 4(5):340-346. 
Momen M. M. Ahmed et al., Irregularity effects on the seismic performance of $l$-shaped .........

[2] LindeburgM.R.,M. Baradar(2001). "Seismic Design of Building Structures: A Professional's Introduction to Earthquake Forces and Design Details." $8^{\text {th }}$ eds. Professional publications, Inc. Belmont, CA, USA.

[3] SolomonA.,G. Hemalatha (2013). "Limitation of irregular structure for seismic response." International Journal of Civil and Structural Engineering3(3): 579-590.

[4] Murty C. V. R. (2005). "IITK-BMTPC Earthquake Tips:Learning Seismic Design and Construction."The second ICI-Asian (ACECON-2005)conference, September 2005, 15-21.

[5] Sakale R., R. Arora,J. Chouhan (2014). "Seismic behavior of buildings having horizontal irregularities."International Journal of Structural and Civil Engineering Research 3(4): 77-84.

[6] Rajalakshmi K., S. Harinarayanan,J. A. Varughese,K. Girija(2015). "Study of Torsion Effects on Building Structures Having Mass and Stiffness Irregularities." International Journal of Engineering Research and Technology, ESRSA Publications4(6): 1318-1325.

[7] BanginwarR. S., M. Vyawahare,P. Modani (2012). "Effect of Plans Configurations on the Seismic Behaviour of the Structure by Response Spectrum Method." International Journal of Engineering Research and Applications (IJERA)2(3): 1439-1443.

[8] Yousuf M.,P. Shimpale (2013). "Dynamic Analysis of Reinforced Concrete Building with Plan Irregularities."International Journal of Emerging Technology and Advanced Engineering3(9): 110-116.

[9] Bele K. R.,S. Borghate (2015). "Dynamic Analysis of Building with Plan Irregularity."Journal of Civil Engineering and Environmental Technology2(11): 23-30.

[10] Sadashiva V., G. MacRae, B. Deam (2010). "Simple Methods to Evaluate Structural Irregularity Effects." New Zealand Society of Earthquake Engineering Conference (NZSEE), Wellington, New Zealand, 26th - 28th March 2010,Paper ID 12.

[11]Abdel Raheem S. E. (2013). "Evaluation of Egyptian code provisions for seismic design of moment-resistingframe multi-story buildings." International Journal of Advanced Structural Engineering (IJASE)5(1): 1-18.

[12] Abdel Raheem S. E., M. M. Ahmed and T. M. Alazrak (2015). "Soil-structure interaction effects on seismic response of multi-story buildings on raft foundation."International Journal of Advanced Structural Engineering (IJASE) 7(1): 11-30.

[13] Charleson A. (2009). Seismic Design for Architects.Taylor \& Francis Group LtdAbingdon, Oxford, UK

[14] Shreyasvi C.,B. Shivakumaraswamy (2015). "A Case Study on Seismic Response of Buildings with Re-Entrant Corners." International Journal of Engineering Research and Technology, ESRSA Publications4(5): 1071-1078.

[15] Arnold C.,R. Reitherman (1982). Building configuration and seismic design, John Wiley \& Sons.

[16] Divyashree M., B. N.Bhavyashree, G Siddappa (2014). "Comparison of bracings and shear walls as seismic strengthening methods to buildings with plan irregularities." International Journal of Research in Engineering and Technology3(18): 205-210.

[17] Divyashree M.,G. Siddappa (2014). "Seismic Behavior of RC Buildings with Re-entrant Corners and Strengthening."IOSR Journal of Mechanical and Civil Engineering (IOSR-JMCE) 3: 63-69.

[18] Goel R. K., A. K.Chopra (1991). "Inelastic seismic response of one-storey, asymmetric-plan systems: Effects of system parameters and yielding."Earthquake Engineering \& Structural Dynamics 20(3): 201-222.

[19] Goel R. K.,A. K.Chopra (1992). "Evaluation of seismic code provisions for asymmetricplan systems."Earthquake Engineering: 10thWorld Conference on Earthquake Engineering (10WCEE), 19-24 July, 1992, Balkema, Rotterdam, 5735-5740.

[20] Petti L., M. De Iuliis (2008). "Torsional seismic response control of asymmetric-plan systems by using viscous dampers." Engineering and Structures 30(11): 3377-3388.

[21] Lin j. 1., K. C. Tsai , M. C. Chuang (2012). "Understanding the trends in torsional effects in asymmetric-plan buildings." Bulletin of Earthquake Engineering 10(3): 955-965

[22] Murty C. V. R., V. A. R. Rupen Goswami, V. M. Vipul (2013). "Some concepts in Earthquake Behaviour of Buildings." Gujarat State Disaster Management Authority, Government of Gujarat.

[23] FEMA (2006). "Designing for Earthquakes-A Manual for Architects,Number 454 " Risk Management Series.

[24] Alavi, A. and P. S. Rao (2013). "Effect of Plan Irregular RC Buildings In High Seismic Zone." Australian Journal of Basic and Applied Sciences: 1-6.

[25] Elnashai A. S.,L. Di Sarno (2008). Fundamentals of earthquake engineering, 1st edition, Wiley New York. 
[26] Kumar D. B. N., A. Gornale (2012). "Seismic Performance Evaluation of Torsionally Asymmetric Buildings." International Journal of Science and Engineering Research3(6): 1-11.

[27]ECP-201 (2008). "Egyptian Code for Calculating Loads and Forces in Structural Work and Masonry." Housing and Building National Research Center, Ministry of Housing, Utilities and Urban Planning, Cairo, Egypt.

[28]ECP-201 (2012). "Egyptian Code for Calculating Loads and Forces in Structural Work and Masonry." Housing and Building National Research Center, Ministry of Housing, Utilities and Urban Planning, Cairo, Egypt.

[29] UBC (1997). "Uniform Building Code, Vol. 2: Structural Engineering Design Provisions." International Conference of Building Officials (ICBO), Whittier, California.

[30] EC8 (2004). "Eurocode 8 - Design of Structures for Earthquake Resistance. Part 1: General Rules, Seismic actions and rules for buildings." European Committee for Standardization, EN 1998-1", Brussels, Belgium.

[31] AIJ (1999). "Design Guidelines for Earthquake Resistant Reinforced Concrete Structures." Architectural Institute of Japan, Tokyo.

[32] Thuat D. V. (2014). "Strength reduction factor demands for building structures under different seismic levels." The Structural Design of Tall and Special Buildings23(1): 42-53.

[33] Suryawanshi M. S. N., S. Kadam,S. Tande (2014)."Torsional Behaviour of Asymmetrical Buildings in Plan under Seismic Forces."International Journal of Emerging Engineering Research and Technology-IJERT2(4):170-176.

[34] Kappos A. (2001). Dynamic loading and design of structures, CRC Press, Taylor \& Francis Group.

[35] Crowley H.,R. Pinho (2010). "Revisiting Eurocode 8 formulae for periods of vibration and their employment in linear seismic analysis." Earthquake Engineering \& Structural Dynamics 39(2): 223-235.

[36] Kunnath S. K.,E. Kalkan (2004). "Evaluation of seismic deformation demands using nonlinear procedures in multistory steel and concrete moment frames." ISET Journal of Earthquake Technology41(1): 159-181.

[37] ASCE (2005). "Building code requirements for structural concrete and Commentary American Concrete Institute. ", USA.

[38] NBCC (2005). "National Building Code of Canada." 12th ed, Canadian Commission on Building and Fire Codes, National Research Council of Canada (NRCC), Ottawa, Ont.

[39] Zheng N., Z. Yang, C. Shi,Z. Chang (2004). Analysis of criterion for torsional irregularity of seismic structures. 13th World conference on earthquake engineering, Vancouver, Canada, August 1-6, Paper No. 1465.

[40] Computers and Structures, Inc., ETABS 2013: integrated building design software, Berkeley, California, USA

[41] Computers and Structures, Inc., SAFE12: design of slabs, beams and foundations reinforced and post-tensioned concrete software, Berkeley, California, USA

[42] ECP-203 (2007). "Egyptian Code for Design and Construction of Reinforced Concrete Structures, ECPCS-203." Housing and Building National Research Center, Ministry of Housing, Utilities and Urban Planning, Cairo, Egypt.

[43] Sujatha A. (2014). "Seismic Performance of Irregular Buildings." Indian Journal of Science and Technology7(3): 1.

[44] Kwon O. S., E. S. Kim (2010). "Evaluation of building period formulas for seismic design." Earthquake Engineering \& Structural Dynamics39(14): 1569-1583.

[45] Abdel Raheem K. A., S. E. Abdel Raheem, H. M. Soghair, M. H. Ahmed (2010). "Evaluation of seismic performance of multistory buildings designed according to Egyptian code." Journal of Engineering Sciences, Assiut University38(2): 381-402.

[46] Searer G. R., S. A. Freeman (2004). Design drift requirements for long-period structures. 13th World conference on earthquake engineering, Vancouver, BC.

[47] Wada, A. (1991). Drift control method for structural design of tall buildings. Proceedings of 2nd Conference on Tall Buildings in Seismic Regions, 55th Regional Conference, Los Angeles, CA.

[48] Herrera, P., C. G. Soberón (2008). Influence of plan irregularity of buildings. The 14th World Conference on Earthquake Engineering, October 12-17, 2008, Beijing, China, Paper ID 14-05-01-0224.

[49] Özmen G., K. Girgin, Y. Durgun (2014). "Torsional irregularity in multi-story structures." International Journal of Advanced Structural Engineering (IJASE)6(4): 121-131. 
[50] IS (2002). "Criteria for Earthquake resistant design of structures, General provisions and buildings." Bureau of Indian Standards, New Delhi.

[51] Jinjie M., S. Qingxuan, Z. Qi (2008). "Method of performance based seismic evaluation for irregular plane reinforced concrete frame structures." 14th World conference on earthquake engineering, Beijing, China, October 12-17, 2008, Paper ID 14-05-03-0035 .

[52] Diamantidis D. (2009). "Robustness of buildings in structural codes." Joint Workshop of COST Actions TU0601 and E\%\%, Ljubljana, Slovenia, September 21-22, 2009.

[53] Al-Harash M. T., N. Panahshahi, K. Truman (2011). "Inelastic seismic response of reinforced concrete buildings with floor diaphragm openings." PhD Dissertation, Washiton University in St Louis, http://dx.doi.org/10.7936/K71834KQ

[54] ATC (1996). Seismic evaluation and retrofit of concrete buildings, SEISMIC SAFETY COMMISSION, State of California.

[55] Bachmann H. (2003). Seismic Conceptual Design of Buildings: Basic Principles for Engineers, Architects, Building Owners, and Authorities." Swiss Federal Office for Water and Geology Swiss Agency for Development and Cooperation, BWG, Biel. 


\section{تأثير عدم الانتظام الإنشائي علي الأداء الزلزالي

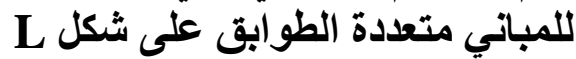

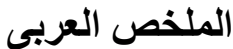

من ملاحظة وفحص أضرار الزلازل في الآونة الأخيرة و علي مدي عقود من الزمن تبين أن المباني

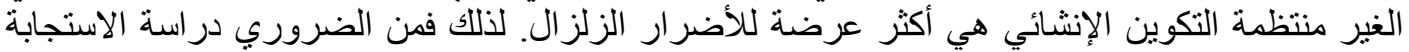

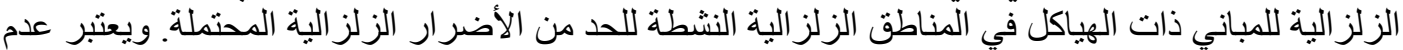

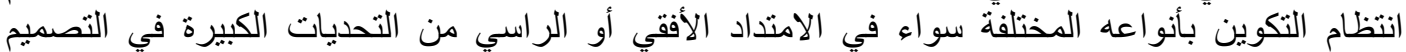

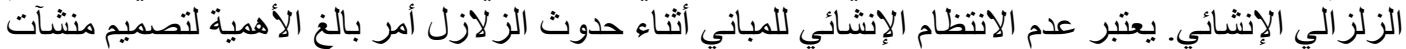

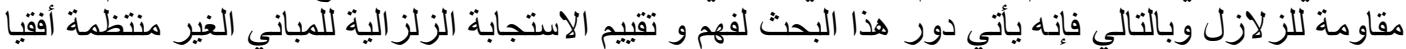

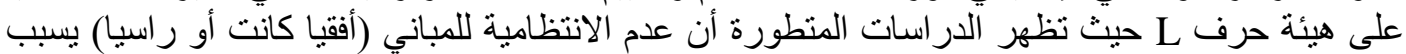

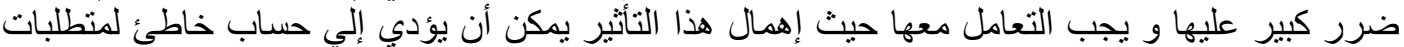

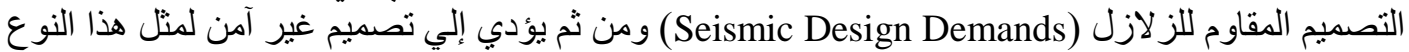

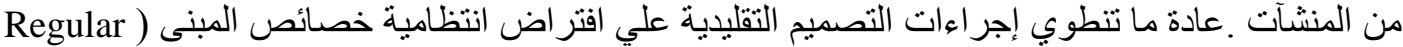
(Configuration

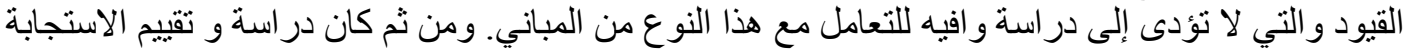

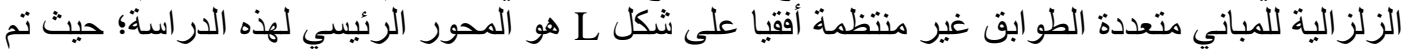

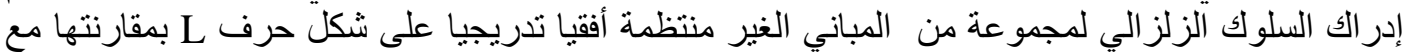

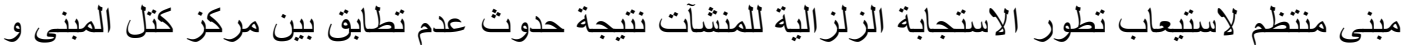

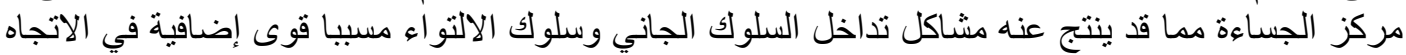

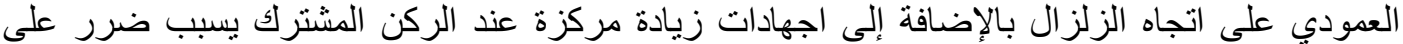

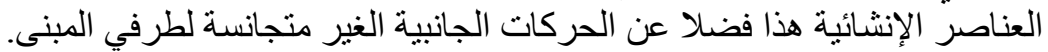

تم تشييد نموذج تحليل عددي ثلاثي الأبعاد باستخدام نظرية العناصر المحددة باستخدام برنامج ETABS

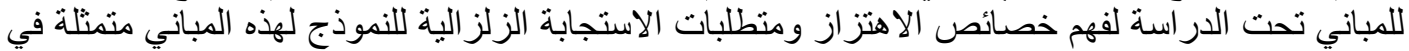

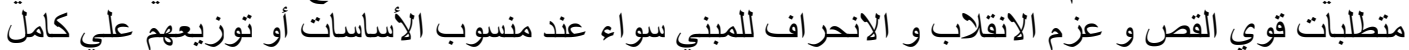

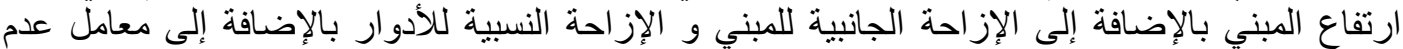

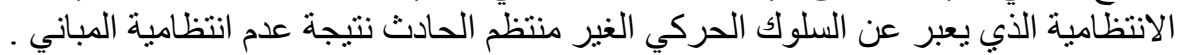

